\title{
Antisense oligonucleotide to insulin-like growth factor II induces apoptosis in human ovarian cancer AO cell line
}

YIN DE LING ${ }^{1}$, LU PU, GANG PEI

Shanghai Institute of Cell Biology, Chinese Academy of

Sciences,320 Yue Yang Road, Shanghai 20031, China

\begin{abstract}
The effects of antisense oligonucleotide to insulin-like growth factor II (IGFII) to induce apoptosis in human ovarian cancer cells were evaluated. Antiproliferation effects of antisense to IGFII in ovarian cancer AO cells were determined by $3 \mathrm{H}$-thymidine incorporation. Apoptosis of the IGFII antisense-treated cells was quantitated by both nuclear condensation and flow cytometry after cells were stained with propidium iodide. IGFII antisense $(4.5 \mu \mathrm{M})$ treatment of $48 \mathrm{~h}$ maximally inhibited proliferation of $\mathrm{AO}$ cells. More than $25 \%$ of IGFII antisense-treated cells (4.5 $\mu M$ for $24 \mathrm{~h}$ ) had undergone apoptosis, whereas less than $3 \%$ of the cells were apoptotic in either IGFII sense-treated cells or untreated cells. Antisense oligonucleotide to IGFII significantly inhibited cell proliferation and induced apoptosis in human ovarian cancer AO cell. These data suggest that IGFII may be a potential target in treatment of ovarian cancer and antisense oligonucleotide to IGFII may serve as a therapeutic approach.
\end{abstract}

Key words: Insulin-like growth factor II (IGFII), antisense oligonucleotide, apoptosis, human ovarian cancer $A O$ cells.

\section{INTRODUCTION}

Ovarian cancer is one of the most common fatal gynesologic malignancies in

1. To whom correspondence should be addressed. 
the world[1]. Clinical treatment of ovarian cancer, though with great progress, has been impeded by resistence to chemical therapy. Recently, induction of apoptosis in cancer cells has become not only a hot topic in basic research but also a focal point in the clinical treatment. Antisense approach has been recently adopted to induce apoptosis in some cancer cells, showing the promosing future for its clinical application.

IGFII is an important growth and/or differentiation factor during normal fetal development and also plays essential roles in many primary human malignant tumors as well as in ovarian cancer cells $[2,3]$. It is thus of great interest to assess the potential effects of inhibition of IGFII expression by antisense oligonucleotide on proliferation and apoptosis in human ovarian cancer cells.

\section{MATERIALS AND METHODS}

\section{Cell culture and drug treatment}

Human ovarian cancer cell line, AO, was obtained from the Cell Bank at the Chinese Academy of Sciences. AO cell line was cultured in RPMI 1640 (Gibco) supplemented with 10\% heat-inactivated fetal calf serum (Evergreen), $100 \mathrm{units} / \mathrm{ml}$ penicillin, $100 \mu \mathrm{g} / \mathrm{ml}$ streptomycin, and $2 \mathrm{mM}$ glutamine. Exponentially growing AO cells $\left(2 \times 10^{4}\right.$ cells $\left./ \mathrm{ml}\right)$ were changed into the medium with $2 \%$ heat-inactivated fetal calf serum and were treated with different concentrations of either IGFII antisense or IGFII sense oligodeoxynuceotides after $12 \mathrm{~h}$.

\section{Sequences of S-oligonucleotides}

The sequences of S-oligonucleotides, synthesized by Sangon Ltd Canada,were as follows:

IGFII antisense: $\quad 3$ ' TAC CCT TAC/G GGT TAC CCC TTC 5'

IGFII sense: $\quad$ 5' ATG GGA ATG/C CCA ATG GGG AAG 3'

\section{Assay for inhibition of ${ }^{3} \mathrm{H}$-thymidine incorporation}

AO cells were plated in sextuplicate wells in 96-well microtest plates, and treated as described[4]. At various intervals after either IGFII antisense or IGFII sense were added, the cells were pulsed with $2 \mu \mathrm{Ci}\left[{ }^{3} \mathrm{H}\right]$-thymidine/well (22 Ci/mmol; Shanghai Institute of Nuclear Sciences, Chinese Academy of Sciences), trypsinized, and harvested on strips of fiberglass filter paper with a multiple automated sample harvesters. The radioactivity of each sample was measured in a liquid scintillation counter.

\section{Morphological analysis of apoptotic cells}

Random fields of control or treated cells were photographed through a $40 \mathrm{x}$ objective lens in both phase and fluoresent modes. Apoptotic cells, after staining with propidium iodide (PI, Sigma) as described[5], were much smaller than the viable cells and presented a condensed chromatin and the fragmented nuclear chromatin bodies[6].

\section{Quantitative analysis of apoptosis}

The cells $\left(2 \times 10^{6}\right)$ treated with $4.5 \mu M$ IGFII antisense or $4.5 \mu M$ IGFII sense or none were washed twice with PBS containing $0.1 \%$ glucose, and then fixed in $1 \mathrm{ml}$ of ice-cold ethanol overnight at $4{ }^{\circ} \mathrm{C}$. The fixed cells were pelleted and resuspended in $0.5 \mathrm{ml}$ of PBS containing $0.1 \%$ glucose, 30 $\mu \mathrm{g} / \mathrm{ml}$ PI, and $1 \mathrm{mg} / \mathrm{ml} \mathrm{RNAse} \mathrm{A} \mathrm{(Sigma).} \mathrm{The} \mathrm{DNA} \mathrm{contents} \mathrm{of} \mathrm{the} \mathrm{cells} \mathrm{were} \mathrm{analyzed} \mathrm{by} \mathrm{Flow}$ Cytometry (Becton-Dickinson, San Jose, CA) as described[7, 8]. 


\section{Cell viability analysis}

Cell viability analysis was performed by conventional trypan blue exclusion[9]. $3 \times 10^{5}$ cells were plated in 6 -well plates. After $24 \mathrm{~h}$, the cells were changed to the medium with $2 \%$ heat-inactivated fetal calf serum and incubated for $12 \mathrm{~h}$. IGFII antisense or IGFII sense oligonucleotides were added to the medium and incubated for another $24 \mathrm{~h}$. Then, the cells were trypsinized and viable cells that excluded trypan blue exclude were counted under a phase microscope. Independent experiments were carried out for at least three times, and the data were given as the means \pm SEM.

\section{Statistics}

Statistical analyses of data were performed using Student's t-test

\section{RESULTS}

\section{Inhibition of cell proliferation by IGFII antisense}

Proliferation of human ovarian cancer AO cells was dramatically inhibited by IGFII antisense treatment (Fig 1 ) and the cell viability of AO cells was greatly reduced by IGFII antisense treatment too (Fig 2). The inhibition by IGFII antisense was dose- and time-dependent. Significant inhibition occurs at $24 \mathrm{~h}$ after application of $1.5 \mu M$ IGFII antisense and at $12 \mathrm{~h}$ after application of $4.5 \mu M$ IGFII antisense. In contrast, treatment of cells with $4.5 \mu M$ IGFII sense oligonucleotide for $48 \mathrm{~h}$ did not show any significant inhibition. IGFII antisense treatment at $4.5 \mu M$ for $24 \mathrm{~h}$ (more than $40 \%$ inhibition) was used for the subsequent experiments.

\section{Morphological changes induced by IGFII antisense consistent with apoptosis}

The effects of IGFII antisense on the morphology of AO cells were examined using fluorescent staining of nuclear DNA with PI. Treatment of AO cells with $4.5 \mu M$
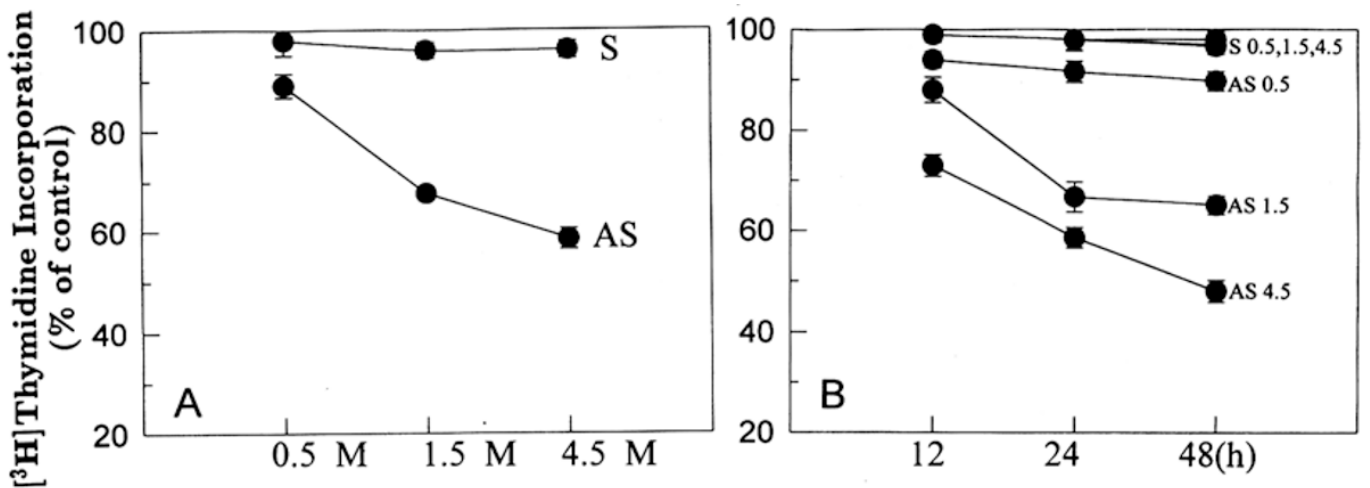

Fig 1. Effects of IGFII antisense and IGFII sense on ${ }^{3} \mathrm{H}$-thymidine incorporation of AO cells. (A) The dose-response curves after $24 \mathrm{~h}$ treatment. (B) The time courses of treatments with different concentration of oligonucleotides. The percentages of ${ }^{3} \mathrm{H}$ thymidine incorporation of the treated samples were calculated against untreated cells. At least three independent experiments each done in sextuplicate were performed to obtain means and SEM. Symbols: $\mathrm{S}$, Sense; AS, Antisense. 

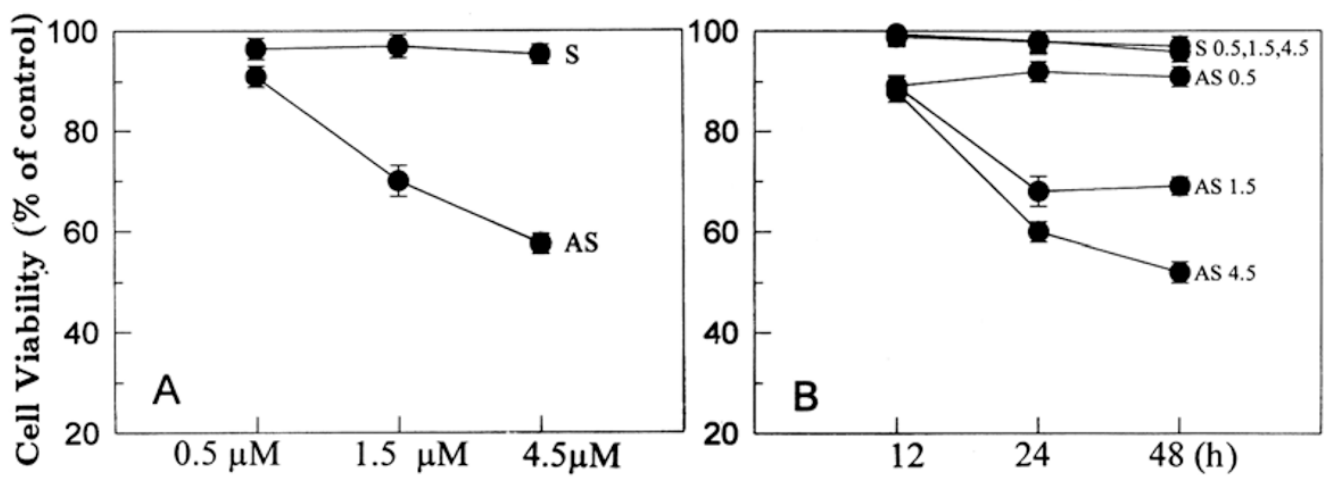

Fig 2. Effects of IGFII antisense and IGFII sense on cell viability of AO cells. (A) The doseresponse curves of effect of IGFII antisense and sense on the cell viability of AO cells after $24 \mathrm{~h}$ treatment. (B) The time course of cell viability of AO cells. The percentages of cell viability of the treated samples were calculated against untreated cells. At least three independent experiments each done in sextuplicate were performed to obtain means and SEM. Symbols: S, Sense; AS, Antisense.
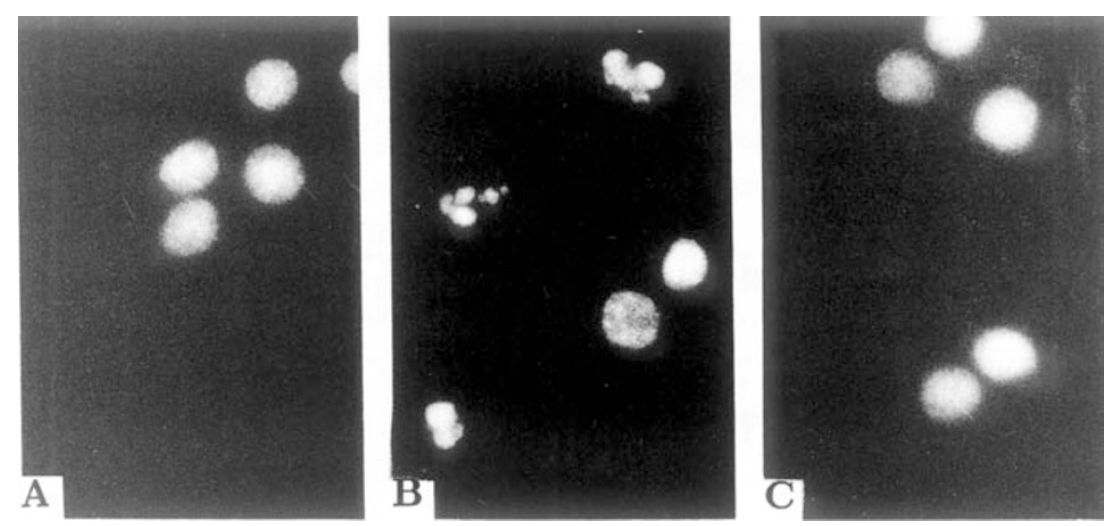

Fig 3. Effects of IGFII antisense and IGFII sense oligonucleotides treatments on the morphology of AO cells. Cultured cells were treated for $24 \mathrm{~h}$ with $4.5 \mu M$ IGFII antisense or 4.5 $\mu M$ IGFII sense or control medium, fixed with methanol:acetic acid (3:1), and stained for $15 \mathrm{~min}$ with PI $(30 \mu \mathrm{g} / \mathrm{ml}$ in PBS). The slides loaded with cells were washed, mounted in PBS, and observed under fluorescence microscope. Representative pictures are shown in (A) for control cells, in (B) for $4.5 \mu M$ IGFII antisense and in (C) for $4.5 \mu M$ IGFII sense-treated cells. The control and $4.5 \mu M$ IGFII sense-treated cells show intact nuclei but the $4.5 \mu M$ IGFII antisense-treated cells demonstrate signs of apoptosis, with condensation of nuclear masses at the nuclear membrane and nuclear fragmentation. 
Yin DL et al.

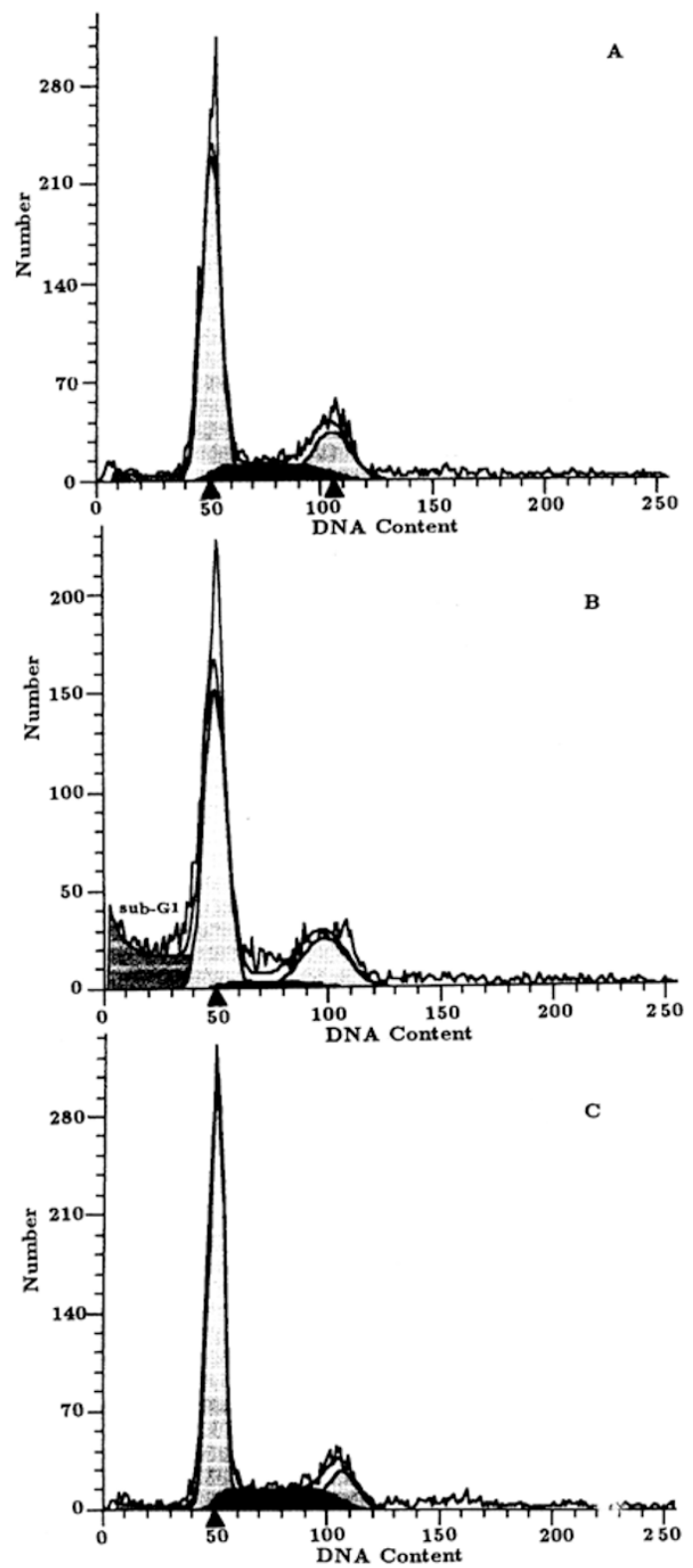

Fig 4. Fluorescence histograms of AO cells after treated with $4.5 \mu \mathrm{M}$ IGFII antisense or $4.5 \mu \mathrm{M}$ IGFII sense for $24 \mathrm{~h}$. Representative histograms of DNA analysis by flow cytometry $(n=3)$ were shown as indicated for control cells (A), $4.5 \mu \mathrm{M}$ IGFII antisense-treated cells (B), $4.5 \mu \mathrm{M}$ IGFII sense-treated cells (C). $\mathrm{X}^{2}$ analysis showed the $4.5 \mu \mathrm{M}$ IGFII antisenseinduced apoptosis as measured by the area under subG1 peak in the histograms were significant higher than that in the control and in the $4.5 \mu \mathrm{M}$ IGFII sensetreated cells $(\mathrm{P}<0.01)$. Xaxis represents fluorescence intensity and Y-axis stands for relative cell numbers.

IGFII antisense for $24 \mathrm{~h}$ (Fig 3) resulted in morphological changes including condensation of chromatin at the nuclear membrane and nuclear fragmentation with groups of isolated pieces of condensed chromatin, which are characteristic of apoptosis 
Antisense to IGFII induces apoptosis in AO cells

\section{Flow cytometry analysis of IGFII antisense-induced apoptosis}

Flow cytometry was applied to further analyze apoptosis induced by IGFII antisense in human ovarian cancer AO cells. $24 \mathrm{~h}$ after incubation of the cells with 4.5 $\mu M$ IGFII antisense, the apoptotic cells, as represented by the sub-G1 peak in the sample histograms (Fig 4), reached about $25 \%$ of the total cell number. The apoptotic cells in the IGFII sense-treated or untreated ovarian cancer AO cells were less than $2 \%$ of the total cell population.

\section{DISCUSSION}

One of direct method of detecting and quantifying apoptosis in cell cultures is to examine the morphology of cells after stained with fluorescent dyes such as PI[6]. A flow cytometry method based on a reduction in DNA staining due to cell shrinkage has been also widely used for detection of apoptosis[10]. Both methods have been used in this study to detect apoptotic effect of IGFII antisense in AO cells.

We have also attempted to detect the DNA fragmentation by gel electrophoresis (laddering) after IGFII antisense treatment of AO cells, but the results showed many smeared bands (data not shown). Although we could not offer the explanation for this, it has been reported that apoptosis occured in several systems without DNA laddering or with atypical DNA laddering[11], and that in other systems necrosis cells also showed a distinct DNA ladder pattern[12]. In spite of this, our results, taken together as a whole, strongly suggest that IGFII antisense indeed prompts apoptosis in human cancer AO cells.

IGF-mediated myoblast survival was accompanied by stimulation of cell proliferation, as indicated by enhanced entry into $\mathrm{S}$ phase of the cell cycle and by increased cell number. IGFII, as an autocrine survival factor, was shown to be required for the survival of cultured hematopoietic cells after trophic factor withdrawal to prevent apoptosis, and to block death of a variety of tumor cell lines cultured for short term[13]. IGFII is also identified as the growth factor required for full tumorigenesis in transgenic mice expressing simian Virus $40 \mathrm{~T}$ antigen in the islets of Langerhans. In the absense of IGFII action, these islet cells show an enhanced rate of death and reduced tumor formation. In this study, it is further demonstrated that blocking IGFII expression using IGFII antisense oligonucleotides indeed promotes programmed cell death of human ovarian cancer AO cells.

S-oligonucleotides (phosphorothioate oligomers) have a sulfur residue instead of an oxygen residue linked to the phosphorus atom of the nucleotide backbone, they are considerably more resistant against eukaryotic endo- and exonucleases than unmodified single-stranded DNA, this is important for their use as prolonged gene suppressors. S-oligonucleotides have also been shown to be actively transported into the cell by a transporter protein. Most of the S-oligonucleotides appears to be located in the cytoplasm after extracellular application[14]. In summary, our results demonstrate that programmed cell death can be induced by inhibition of IGFII ex- 
pression in human ovarian cancer AO cells, therefore, IGFII antisense could be a useful tool, with potential clinical application, to induce apoptosis in human ovarian cancer cells.

\section{ACKNOWLEDGEMENTS}

This research was supported by research grants from National Natural Science Foundation of China (No: 39600157), Chinese Academy of Sciences, Shanghai Research Centre of Life Science, and German Max-Planck Society. The authors thank Dr. Lan MA, Li-Zhen JIANG, Yan-Ping WANG for their help.

\section{REFERENCES}

[1] Langdon SP, Ritchie A, Young K, et al. Contrasting effects of $17 \beta$-estradiol on the growth of human ovarian carcinoma cells in vitro and vivo. Int J Cancer 1993; 55:459-64.

[2] Stewart CE, Rotwein P. Growth, differentiation, and survival: multiple physiological functions for insulin-like growth factors. Physiol Rev 1996; 76(4):1005-26.

[3] Ho MN, Delgado CH, Owens GA, Steller MA. Insulin-like growth factor-II participates in the biphasic effect of a gonadotropin-releasing hormone agonist on ovarian cancer cell growth. Fertil Steril 1997; 67(5):870-6.

[4] $\mathrm{Bu} \mathrm{SZ}$, Yin DL, Ren XH, et al. Progesterone induces apoptosis and up-regulation of p53 expression in human ovarian carcinoma cell lines. Cancer 1997; 79:1944-50.

[5] Yin DL, Ren XH, Zheng ZL, et al. Etorphine inhibits cell growth and induces apoptosis in SK-N-SH cells: involvement of pertussis toxin-sensitive G proteins. Neurosci Research 1997; 29(2):121-7.

[6] Coucouvanis EC, Martin GR, Nadeau JH. Genetic approaches for studying programmed cell death during development of the laboratory mouse. In: Schwartz LM, Osborne BA. eds. Cell death. Methods in Cell Biology 1995; 46:397-9.

[7] Yin DL, Ren XH, Bu SZ, et al. Induction of apoptosis and changes of bcl-2 expression in macrophage Ana-1 cells by all-trans retinoic acid. Cell Research 1996; 6:137-44.

[8] Dolbeare F, Gratzner H, Pallavicinl MG, Gray JW. Flow cytometric measurement of total DNA content and incorporated bromodeoxyuridine. Proc Natl Acad Sci USA 1983; 80:5573-7.

[9] McGahon AJ, Martin SJ, Bissonnette RP, et al. The end of the cell line: methods for the study of apoptosis in vitro In: Schwartz LM, Osborne BA. eds. Cell death. Methods in Cell Biology $1995 ; 46: 165-9$.

[10] Telford WG, King LE, Fraker PJ. Rapid quantitation of apoptosis in pure and heterogeneous cell population using flow cytometry. J Immunol Methods 1994; 172:1-16.

[11] Oberhammer F, Burseh W, Tiefenbacher R, et al. Apoptosis is induced by transforming growth factor-beta1 within $5 \mathrm{~h}$ in regressing liver without significant fragmentation of the DNA. Hepatology 1993; 18:1238-46.

[12] Fukuda K, Kojiro M, Chiu JF. Demonstration of extensive chromatin cleavage in transplanted morris hepatoma 7777 tissue: apoptosis or necrosis? Am J Pathol 1993; 142:935-46.

[13] Stewart CE, Rotwein P. Insulin-like growth factor-II is an autocrine survival factors for differentiating myoblasts. J Biol Chem 1996; 271:11330-8.

[14] Schlingensiepen KH, Brysch W. Phosphorothioate Oligomers. In: Erickson RP, Izant JG. eds. Gene regulation: Biology of antisense RNA and DNA. Raven Press: New York 1992:317-9.

Received Nov-18-1997. Revised Jan-8-1998. Accepted Jan-29-1998. 